\title{
Tissue identification with micro-magnetic resonance imaging in a caprine spinal fusion model
}

\author{
M. P. Uffen · M. R. Krijnen · R. J. Hoogendoorn • \\ G. J. Strijkers · V. Everts · P. I. Wuisman · \\ T. H. Smit
}

Received: 8 November 2007 / Revised: 6 April 2008 / Accepted: 30 April 2008/Published online: 30 May 2008

(C) The Author(s) 2008

\begin{abstract}
Nonunion is a major complication of spinal interbody fusion. Currently X-ray and computed tomography (CT) are used for evaluating the spinal fusion process. However, both imaging modalities have limitations in judgment of the early stages of this fusion process, as they only visualize mineralized bone. Magnetic resonance imaging (MRI) could be of great value as it is able to discriminate between different types of tissue. A feasibility
\end{abstract}

M. P. Uffen and M. R. Krijnen contributed equally to the manuscript.

Professor Paul Wuisman passed away on 25 July 2007.

M. P. Uffen · M. R. Krijnen · R. J. Hoogendoorn ·

P. I. Wuisman

Department of Orthopaedic Surgery,

VU University Medical Center,

Amsterdam, The Netherlands

G. J. Strijkers

Biomedical NMR, Department of Biomedical Engineering,

Eindhoven University of Technology,

Eindhoven, The Netherlands

V. Everts

Department of Oral Cell Biology,

Academic Center for Dentistry Amsterdam (ACTA),

Universiteit van Amsterdam and Vrije Universiteit Amsterdam,

Amsterdam, The Netherlands

T. H. Smit $(\bowtie)$

Department of Physics and Medical Technology,

VU University Medical Center, P. O. Box 7057, 1007 MB,

Amsterdam, The Netherlands

e-mail: th.smit@vumc.nl

M. P. Uffen - M. R. Krijnen - R. J. Hoogendoorn - V. Everts ·

P. I. Wuisman · T. H. Smit

Skeletal Tissue Engineering Group Amsterdam (STEGA),

Amsterdam, The Netherlands study was performed in nine animals from a goat spinal fusion study, to evaluate the detection capacity of different tissues with micro-MRI. In this study bioresorbable polylactic acid cages were used. Six- and 12-months follow-up specimens were scanned in a $6.3 \mathrm{~T}$ micro-MRI scanner. After scanning, the specimens were processed for histology. Different types of tissue as well as the degradable cage material were identified in the fusion zone and designated as regions of interest (ROIs). Subsequently, the location of these ROIs was determined on the corresponding microMRI image, and average signal intensities of every individual ROI were measured. An excellent match was seen between the histological sections and micro-MRI images. The micro-MRI images showed quantifiable differences in signal intensity between bone with adipose marrow, bone with hematopoietic marrow, fibrocartilage, fibrous tissue, and degradable implant material. In time the signal intensity of bone with adipose marrow, bone with hematopoietic red marrow, and of fibrous tissue remained relatively constant. On the other hand, the signal intensity of the degradable implant material and the fibrocartilage changed significantly in time, indicating change of structure and composition. In conclusion, in our model using bioresorbable cages the MRI provides us with detailed information about the early fusion process and may therefore, allow early diagnosis of non-union.

Keywords Spine - Interbody fusion .

Bioresorbable implant · Micro-MRI · Histology

\section{Introduction}

Spinal fusion essentially is a process of bone formation, which is influenced by a variety of biomechanical, 
biochemical, cellular, and hormonal mechanisms [9]. As in fracture repair, mechanical stability is a prerequisite for successful bone formation at the spinal fusion site. Excessive motion of the segments may lead to complications like pseudo-arthrosis or non-union with cartilage and/or fibrous tissue formation [2, 4, 21]. Non-union, in fact, is one of the most frequent complications of arthrodesis [28]. In the spine, however non-union is difficult to diagnose at an early stage, as half of the patients with a non-union are reported to be asymptomatic [22, 26].

Plain radiographs are the most commonly used imaging technique to evaluate the fusion process. Trabecular bone, crossing at the fusion site on antero-posterior and lateral projections is used to assess consolidation of the bone graft [16]. However, plain radiography is accurate in only 59 to $82 \%$ of the cases with a high specificity and a low sensitivity $[3,6,10,20,26]$. Another disadvantage inherent to radiographic imaging techniques is the inability to visualize soft tissue or radiolucent materials that are used in cages [31]. When metallic implants are used, accurate assessment of the fusion zone inside the cage is impossible due to the radiopacity of metallic cages [29, 30, 32]. During the past several years, computed tomography (CT) has become one of the most important diagnostic modalities in the evaluation of spinal interbody fusion. CT can create 3D images and slices, demonstrating the presence or absence of bone bridging between the vertebral bodies $[8$, 15]. However, none of the previously described disadvantages of X-ray evaluation are overcome by CT. Furthermore, CT comes at the costs of considerable radiation doses [24].

Recent studies show that MRI can detect changes in soft tissues over time [1, 17-19, 27]. Furthermore, processes inside the cage can be monitored with MRI, especially when bioresorbable cage material is used. Moreover, MRI provides information on the position of the cage after surgery and may show the time dependent degradation of bioresorbable spinal implants [11]. These advantages of MRI, combined with the absence of radiation exposure to the patient, could make MRI scanning a valuable diagnostic tool for monitoring the fusion process.

In the present study we analyzed the feasibility of micro-MRI analysis to study the process of fusion inside a bioresorbable PLDLA cage in a goat model and quantified these micro-MRI measurements on a scale. For this purpose, histological sections were analyzed and compared with corresponding micro-MRI images. The signal intensity of the different tissues in the MRI images was subsequently quantified and tissue specific differences were determined for developing a micro-MRI tissue grading scale.

\section{Materials and methods}

Animal model and study design

Micro-MRI images and histological slices were obtained from nine goats used in a previously described caprine spinal fusion model study $[11,12]$. In this study, the L3-L4 vertebral segments of the lumbar spine were fixated using a rectangular $(10 \times 10 \times 18 \mathrm{~mm})$ bioresorbable PLDLA cage, filled with impacted autologous bone graft. After creating a defect through both endplates, the cage was placed laterally between two vertebrae. The surgical procedure, cage, and implantation procedure have been described in detail elsewhere [11]. The follow-up was 6 $(n=3)$ and 12 months $(n=6)$.

\section{Magnetic resonance imaging}

At autopsy, the treated motion segment (L3-L4) was excised and trimmed of residual musculature. The transverse and spinous processes were removed. The segment was kept at $4^{\circ} \mathrm{C}$ and immediately transported to an MR unit.

The MR imaging experiments were performed using a 6.3 T MR imaging scanner with a $9.5 \mathrm{~cm}$ diameter horizontal bore, equipped with a Varian VXR-S imaging console (Varian Associates, Palo Alto, CA). The MR imaging studies were started approximately $3 \mathrm{~h}$ after sacrificing the animals. The segments were wrapped in plastic and inserted into a $5.5 \mathrm{~cm}$ diameter, linear driven birdcage radio frequency coil. The experiments were performed at room temperature. Depending on the size of the specimen, 21 to 35 slices were recorded; the slice thickness was $1 \mathrm{~mm}$, there was no gap between them. The in-plane field of view for all images was $5.5 \times 5.5 \mathrm{~cm}^{2}$. High resolution MR images (proton density) were acquired (transverse and sagittal plane) using a standard spin echo sequence with a repetition time of $4 \mathrm{~s}$, an echo time of $15 \mathrm{~ms}$, and 12 signal averages. The matrix size was $256 \times 256$, zero-filled to $512 \times 512$, yielding an in-plane resolution of 200 and $100 \mu \mathrm{m}$ in the original and interpolated images, respectively (Fig. 1b).

\section{Histology}

After MR imaging, each segment was sectioned sagitally in a standardized manner, using a water-cooled band saw (EXAKT, Norderstedt, Germany), creating a $5 \mathrm{~mm}$ paramidsagittal section. This section was dehydrated using formaldehyde, embedded in methyl methacrylate and $12 \mu \mathrm{m}$ sections were obtained. All sections were stained with Goldner Trichrome (GT) and Toluidine Blue (TB) (Fig. 1a). 

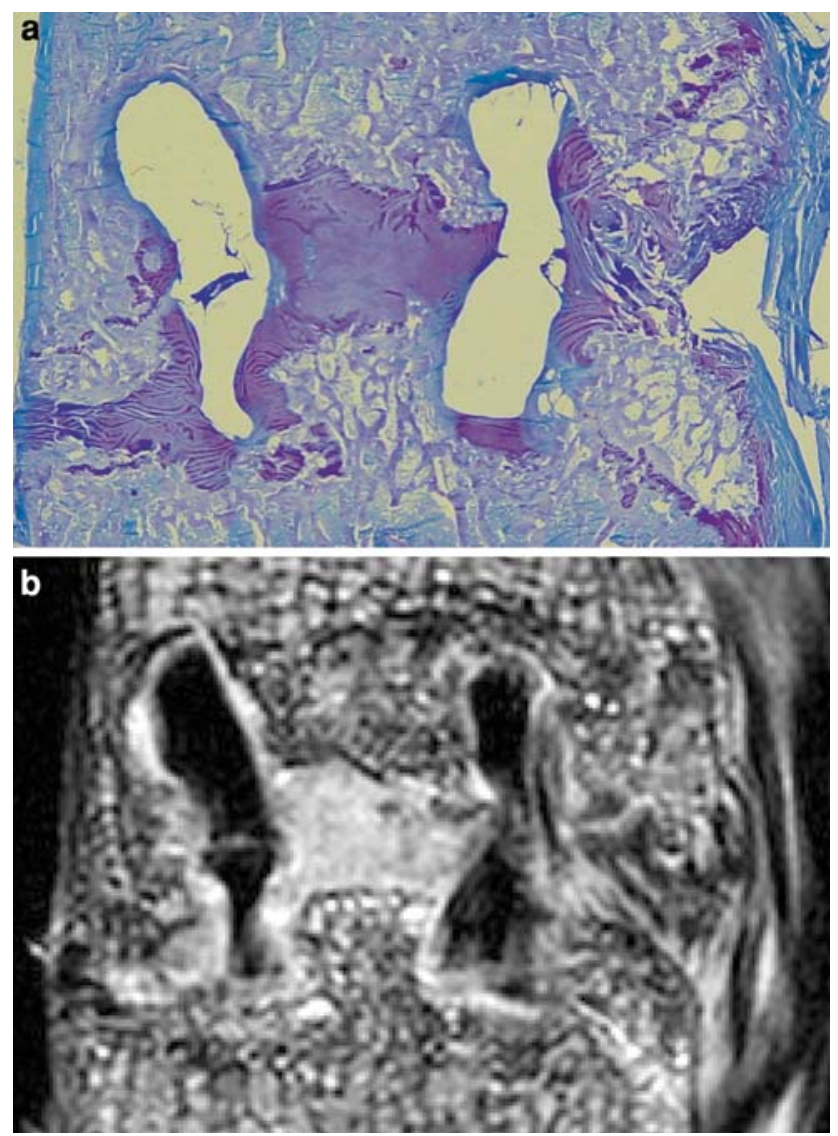

Fig. 1 a Micrograph of a toluidine blue stained specimen of a fused segment after 6 months. Encircled are several ROIs identifying different types of tissue involved in the spinal fusion. b The corresponding micro-MRI image. In the designated ROIs the average signal intensity was determined using image analysis software. Note the low signal intensity of the cage material, the deformation and the cracks

Four different tissues generally present at a fusion site were defined prior to the histological analysis: bone containing hematopoietic marrow (BHM), bone containing adipose marrow (BAM), fibrous tissue (F) and fibrocartilage (FC). Cage material was identified by the absence of cells. The definitions of the tissues used in the present study are shown in Table 1. Regions of interest (ROIs), each containing only one of the four selected tissues or the cage material, were selected by one of the authors (MPU). Subsequently a second observer (VE) classified the tissue in each ROI on every histological section. When both observers independently agreed on the nature of the tissue in a ROI, it was included in the study. This resulted in tissue specific ROIs in all of the histological sections for all four different tissues as well as cage material.

Magnetic resonance imaging analysis and assessment

For each histological section, the corresponding microMRI image was selected using ImageJ, a public domain,
Table 1 Abbreviations and definitions used for analyzed histological tissues

\begin{tabular}{lll}
\hline Tissue & Abbreviation & Definition \\
\hline $\begin{array}{c}\text { Bone with } \\
\text { hematopoietic } \\
\text { marrow }\end{array}$ & BHM & $\begin{array}{c}\text { Presence of hematopoietic } \\
\text { cells and osteocytes }\end{array}$ \\
$\begin{array}{c}\text { Bone with adipose } \\
\text { marrow }\end{array}$ & BAM & $\begin{array}{c}\text { Presence of adipose cells and } \\
\text { osteocytes }\end{array}$ \\
$\begin{array}{l}\text { Fibrous tissue } \\
\text { Presence of fibroblasts and } \\
\text { collagenous fibers }\end{array}$ \\
$\begin{array}{l}\text { Fibrocartilage } \\
\text { Cage material }\end{array}$ & F & $\begin{array}{c}\text { Presence of (rows of }) \\
\text { chondrocytes } \\
\text { Absence of cells }\end{array}$ \\
\hline
\end{tabular}

${ }^{a}$ Bone defined as tissue containing osteocytes, hematopoietic marrow defined as tissue containing hematopoietic cells, and adipose marrow defined as tissue containing adipose cells

Java-based image processing program (National Institutes of Health, Bethesda, MD, USA). Subsequently, the previously identified ROIs were identified in the MRI images (Fig. 1b). The signal intensity of each ROI was determined using ImageJ. Considerable variation in the absolute value of the signal intensities was observed. Therefore, fibrous tissue was selected as baseline because the signal intensity of this tissue was stable and remained stable during the follow-up period. The signals of all tissues were expressed as a ratio of fibrous tissue.

Statistical analysis

Statistical analysis software was used to analyze the data (Instat. Graph pad Software Inc, San Diego, USA). Repeated measures ANOVA with a Tukey-Kramer post-hoc test was used to determine differences between tissue signal intensities. The Student $t$ test was used to analyze differences between both time-points.

\section{Results}

\section{Histology}

The selected tissues were identified in all specimens by both observers. The cages were clearly detectable in all specimens. After 6 months, the cages in general showed considerable deformation and fracturing. After 12 months, all six cages had disintegrated, migrated and were deformed (Fig. 1b). At both time points, all cages were surrounded by a thin layer of fibrous tissue, gradually changing into fibrocartilage in the fusion zone and at the load bearing edges of the cage.

The relative signal intensities and their relation to different tissues are shown in Fig. 2. The different tissues 


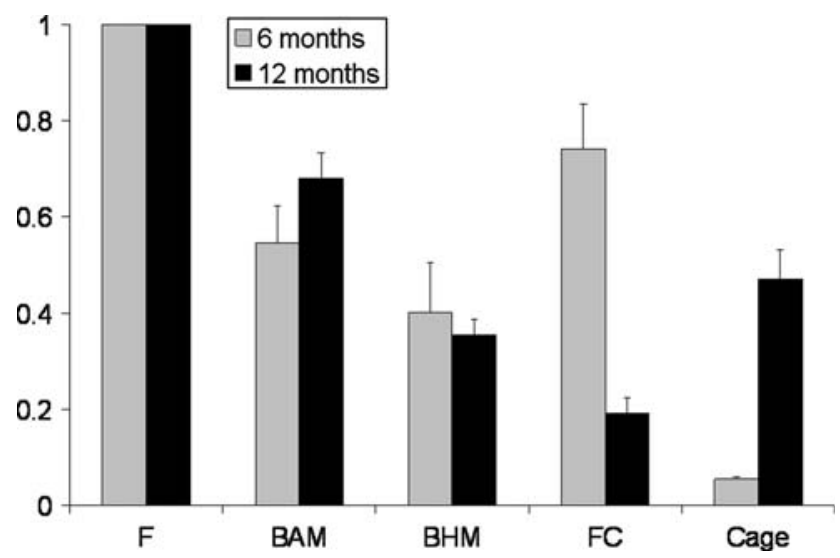

Fig. 2 The ratios of the different tissues analyzed in the present study $( \pm$ SEM). The signal intensity of fibrous tissue is used as a standard (1 by definition). All other tissues are expressed as a ratio of fibrous tissue. Fibrocartilage and cage material signal intensities both changed during the follow-up. $* p<0.05$ as compared between follow-up time-points (Student $t$ test)

Table $2 P$-values of differences between different types of tissue and cage material at 6 months (vertical, bold italic), 12 months (horizontal, italic) and between follow-up time-points within selected tissues (bold)

\begin{tabular}{|c|c|c|c|c|c|}
\hline \multirow[t]{2}{*}{12 months } & \multicolumn{5}{|c|}{6 months } \\
\hline & $\mathrm{F}$ & BAM & BHM & $\mathrm{FC}$ & C \\
\hline $\mathrm{F}$ & NS & $<0.001$ & $<0.001$ & $<0.05$ & $<0.001$ \\
\hline BAM & $<0.001$ & NS & $N S$ & $N S$ & $<0.01$ \\
\hline BHM & $<0.001$ & $<0.001$ & NS & $<0.05$ & $<0.05$ \\
\hline $\mathrm{FC}$ & $<0.001$ & $<0.001$ & $<0.05$ & $<\mathbf{0 . 0 0 1}$ & $<0.001$ \\
\hline $\mathrm{C}$ & $<0.001$ & $<0.01$ & $N S$ & $<0.001$ & $<\mathbf{0 . 0 0 1}$ \\
\hline
\end{tabular}

$N S=$ not significant

showed significantly different signal intensities as compared to each other, with three exceptions (Table 2): after 6 months; bone with adipose marrow (BAM) versus bone with hematopoietic marrow (BHM), and bone with adipose marrow versus fibrocartilage (FC); and after 12 months, bone with hematopoietic marrow versus cage material. Comparing the signal intensities of BAM and BHM in time did not result in significant changes. The signal intensity of fibrocartilage was higher after 6 months than intensities of BAM, BHM, and cage material (Fig. 2). However, after 12 months the fibrocartilage signal intensity had decreased significantly $(p=0.0002)$ and was significantly lower compared to all other tissues, including the degradable cage material (Fig. 2).

After 6 months, ROIs classified as bioresorbable PLDLA cage were showing the lowest signal intensities (Fig. 2). At 12 months, the cage material showed more deformation and significant higher signal intensities compared to 6 months $(p=0.0025)$.
In the present study the location of the two types of bone marrow was not determined. However, in all sections (both 6 and 12 months) adipose marrow was observed closest to the fusion zone. Both cranially and caudally of the fusion zone, hematopoietic marrow was seen intruding the fusion zone subsequent to adipose marrow.

\section{Discussion}

Rates of spinal fusion procedures are increasing in recent years in the US [7, 32]. The reported rates of failed union in general are high, varying between 0 and 56\% depending on, among others, fixation type and number of levels fused $[5,16]$. However, not all patients with a non-union are symptomatic, complicating the process of diagnosis of nonunion [22]. At this time, the golden standard in diagnosing non-union is surgical exploration [16]. Ideally, a noninvasive tool should be available for assessing the process of fusion in the patient, and predicting outcome of the process at an early stage. Currently, X-ray and CT are clinically used to evaluate spinal fusion. As the fusion process includes different stages with different sorts of soft tissues, more sophisticated imaging techniques are needed to discern the differences between them. We used samples from a spinal fusion goat study to evaluate the micro-MRI signal intensities of tissues involved in interbody fusion. In this study bioresorbable polylactic acid cages were used. We found that the ratios of the tissues analyzed were reproducible and distinguishable from each other using micro-MRI (Fig. 2). Furthermore, we observed that the signal intensity of fibrocartilage and degradable cage material changed during follow-up. We conclude that MRI provides us with vital and detailed information about the early fusion process and may therefore, allow early diagnosis of non-union. At present the use of MRI for this purpose is limited to non-metallic cages.

Fibrocartilage and cage material signal intensities changed significantly in the goat segments between 6 and 12 months (Fig. 2). The lower signal intensity of the fibrocartilage at 12 months indicates a decrease in the content of water. This may be explained by the ongoing deposition of extracellular matrix and maturation of the fibrocartilage. Clear histological changes, however, were not observed in this tissue. By contrast, the signal intensity of the cage material increased during the follow-up (Fig. 2). After 6 months the cages produced low signal intensity (Fig. 1b). After 12 months, however, the signal intensities increased significantly. This change can be explained by the degradation of the cages, which actually occurs through hydrolysis after water penetrates the polymer. This observation is of interest as it was shown before that these PLDLA cages retain their initial strength for 
approximately 6 months [25, 33]. After 6 months their strength gradually decreases and at 12 months the cages entirely lost their mechanical integrity [25]. In a clinical perspective, the signal intensity of the cage can be used as an indicator of its mechanical integrity; loss of mechanical integrity contributes to instability of the spinal segment, which is a risk factor for non-union.

In the present study, in both 6 and 12 months, adipose marrow was observed closest to the fusion zone. Both cranially and caudally of the fusion zone hematopoietic marrow was seen intruding the fusion zone after adipose marrow. This is in line with previous studies in which red (hematopoietic) marrow was found in later stages, indicating that red marrow is related to a more mature bone type $[11,30]$. This is an interesting finding, because adipose marrow is generally found in older persons, whereas, hematopoietic marrow is rather related to bone formation and growth. This study consistently shows a role for adipose bone marrow in the fusion process. The ability to discriminate between red and yellow marrow with MRI also has practical implications, as Lang et al. [14] found that the signal intensity of bone marrow might be related to functional stability of a fused segment.

With respect to future clinical application two methodological aspects of this study need to be addressed. First, the use of a high field MR scanner $(6.3 \mathrm{~T})$ and second the use of an internal reference (fibrous tissue) for signal intensities. The high-field MR scanner was used to obtain high-resolution MR images, which resulted in images of very high quality. Because of its small bore size the present scanner is obviously not suitable in a clinical setting. Furthermore, the current scanning times are too long for clinical application. However, high resolution imaging of bone and cartilage becomes readily available in a clinical setting, with the development of high (3 and 7 T) MR scanners and the development of new and faster MR sequences [23]. The signal intensity of fibrous tissue was used as reference because the absolute pixel intensities in the images varied between MRI measurements. Although the use of an external "standard", e.g., a tube containing water, is preferable, the stable proportions of the different tissues justified the use of this internal "standard". In future (pre) clinical research an external standard will be used.

In the present model a standardized endplate perforation was used. Polylactic acid implants degrade over time mostly by bulk hydrolysis which produces lactic acid. Transportation of this waste product is essential since accumulation will lead to autocatalysis of the implant and bone resorption. To our opinion, opening of the endplates is not only essential for removal of lactic acid but also for the supply of osteogenic cells. A disadvantage of endplate perforation could be subsidence of the segment. A recent
RSA study in the same model has shown that both bioresorbable and the titanium control cages induce less than $1.5 \mathrm{~mm}$ of segment subsidence after 12 months [13], which is largely or completely due to settling of the cage. Complete perforation of the endplates may not be necessary and could lead to subsidence in combination with stiff and sharp implants. However, we feel that endplate preparation with formation of bleeding subchondral bone is vital when using polylactic acid interbody fusion devices.

In contrast to $\mathrm{CT}$ and X-ray, micro-MRI can differentiate between different kinds of soft tissue as well as bone and implant material in our model, using non-metallic cages. The present study demonstrates that there is a clear correlation between micro-MRI signal intensities and the corresponding histological tissues. Our data further show that micro-MRI could be used to analyze the process involved in spinal fusion on tissue level. Moreover, microMRI can be used to monitor the process of degradation of bioresorbable cage material. MRI could play a major role in preclinical development of bioresorbable and other nonmetallic implants. Furthermore, the increasing availability of clinical high resolution MR scanners supports a clinical application of this method in the near future. In conclusion, micro-MRI could be a valuable tool to monitor and evaluate early bone healing for both research purposes and future clinical decision making.

Open Access This article is distributed under the terms of the Creative Commons Attribution Noncommercial License which permits any noncommercial use, distribution, and reproduction in any medium, provided the original author(s) and source are credited.

\section{References}

1. Alikacem N, Stroman PW, Marois Y et al (1995) Noninvasive follow-up of tissue encapsulation of foreign materials. Are magnetic resonance imaging and spectroscopy breakthroughs? ASAIO J 41:M617-M624

2. Augat P, Burger J, Schorlemmer S et al (2003) Shear movement at the fracture site delays healing in a diaphyseal fracture model. $J$ Orthop Res 21:1011-1017

3. Blumenthal SL, Gill K (1993) Can lumbar spine radiographs accurately determine fusion in postoperative patients? Correlation of routine radiographs with a second surgical look at lumbar fusions. Spine 18:1186-1189

4. Carter DR, Beaupre GS, Giori NJ et al. (1998) Mechanobiology of skeletal regeneration. Clin Orthop Relat Res S41-S55

5. Christensen FB (2004) Lumbar spinal fusion. Outcome in relation to surgical methods, choice of implant and postoperative rehabilitation. Acta Orthop Scand Suppl 75:2-43

6. Dawson EG, Clader TJ, Bassett LW (1985) A comparison of different methods used to diagnose pseudarthrosis following posterior spinal fusion for scoliosis. J Bone Joint Surg Am 67:1153-1159

7. Deyo RA, Gray DT, Kreuter W et al (2005) United States trends in lumbar fusion surgery for degenerative conditions. Spine 30:1441-1445 
8. Hojo Y, Kotani Y, Ito M et al (2005) A biomechanical and histological evaluation of a bioresorbable lumbar interbody fusion cage. Biomaterials 26:2643-2651

9. Kalfas IH (2001) Principles of bone healing. Neurosurg Focus 10:E1

10. Kant AP, Daum WJ, Dean SM et al (1995) Evaluation of lumbar spine fusion. Plain radiographs versus direct surgical exploration and observation. Spine 20:2313-2317

11. Krijnen MR, Smit TH, Strijkers GJ et al (2004) The use of highresolution magnetic resonance imaging for monitoring interbody fusion and bioabsorbable cages: an ex vivo pilot study. Neurosurg Focus 16:E3

12. Krijnen MR, Mullender MG, Smit TH et al (2006) Radiographic, histologic, and chemical evaluation of bioresorbable 70/30 polyL-lactide-CO-D, L-lactide interbody fusion cages in a goat model. Spine 31:1559-1567

13. Krijnen MR, Valstar ER, Smit TH, Wuisman PI (2006) Does bioresorbable cage material influence segment stability in spinal interbody fusion? Clin Orthop Relat Res 448:33-38

14. Lang P, Chafetz N, Genant HK et al (1990) Lumbar spinal fusion. Assessment of functional stability with magnetic resonance imaging. Spine 15:581-588

15. Larsen JM, Rimoldi RL, Capen DA et al (1996) Assessment of pseudarthrosis in pedicle screw fusion: a prospective study comparing plain radiographs, flexion/extension radiographs, CT scanning, and bone scintigraphy with operative findings. J Spinal Disord 9:117-120

16. Lee C, Dorcil J, Radomisli TE (2004) Nonunion of the spine: a review. Clin Orthop Relat Res 71-75

17. Liem MD, Zegel HG, Balduini FC et al (1991) Repair of Achilles tendon ruptures with a polylactic acid implant: assessment with MR imaging. AJR Am J Roentgenol 156:769-773

18. Ling CR, Foster MA (1982) Changes in NMR relaxation time associated with local inflammatory response. Phys Med Biol 27:853-860

19. McCully K, Shellock FG, Bank WJ et al (1992) The use of nuclear magnetic resonance to evaluate muscle injury. Med Sci Sports Exerc 24:537-542
20. Pearcy M, Burrough S (1982) Assessment of bony union after interbody fusion of the lumbar spine using a biplanar radiographic technique. J Bone Joint Surg Br 64:228-232

21. Perren SM (2002) Evolution of the internal fixation of long bone fractures. The scientific basis of biological internal fixation: choosing a new balance between stability and biology. J Bone Joint Surg Br 84:1093-1110

22. Raiszadeh R, Heggeness M, Esses SI (2000) Thoracolumbar pseudarthrosis. Am J Orthop 29:513-520

23. Regatte RR, Schweitzer ME (2007) Ultra-high-field MRI of the musculoskeletal system at 7.0T. J Magn Reson Imaging 25:262-269

24. Semelka RC, Armao DM, Elias J Jr et al (2007) Imaging strategies to reduce the risk of radiation in CT studies, including selective substitution with MRI. J Magn Reson Imaging 25:900-909

25. Smit TH, Thomas KA, Hoogendoorn RJ et al (2007) Sterilization and strength of 70/30 polylactide cages: e-beam versus ethylene oxide. Spine 32:742-747

26. Steinmann JC, Herkowitz HN (1992) Pseudarthrosis of the spine. Clin Orthop Relat Res 80-90

27. Stroman PW, Dorvil JC, Marois Y et al (1999) In vivo time course studies of the tissue responses to resorbable polylactic acid implants by means of MRI. Magn Reson Med 42:210-214

28. Turner JA, Ersek M, Herron L et al (1992) Patient outcomes after lumbar spinal fusions. JAMA 268:907-911

29. Vaccaro AR, Singh K, Haid R et al (2003) The use of bioabsorbable implants in the spine. Spine J 3:227-237

30. van Dijk M, Smit TH, Burger EH et al (2002) Bioabsorbable poly-L-lactic acid cages for lumbar interbody fusion: three-year follow-up radiographic, histologic, and histomorphometric analysis in goats. Spine 27:2706-2714

31. Vande Berg BC, Galant C, Lecouvet FE et al (2000) The lumbar vertebral body and diskovertebral junction. Radio MR imaging anatomic correlations. Radiol Clin North Am 38:1153-1175

32. Weinstein JN, Lurie JD, Olson PR et al (2006) United States' trends and regional variations in lumbar spine surgery: 19922003. Spine 31:2707-2714

33. Wuisman PI, van Dijk M, Smit TH (2002) Resorbable cages for spinal fusion: an experimental goat model. J Neurosurg 97:433-439 